\title{
Improved tropospheric and stratospheric sulfur cycle in the aerosol-chemistry-climate model SOCOL-AERv2
}

\section{Supplementary Material}

Aryeh Feinberg, Timofei Sukhodolov, Bei-Ping Luo, Eugene Rozanov, Lenny H.

E. Winkel, Thomas Peter, Andrea Stenke

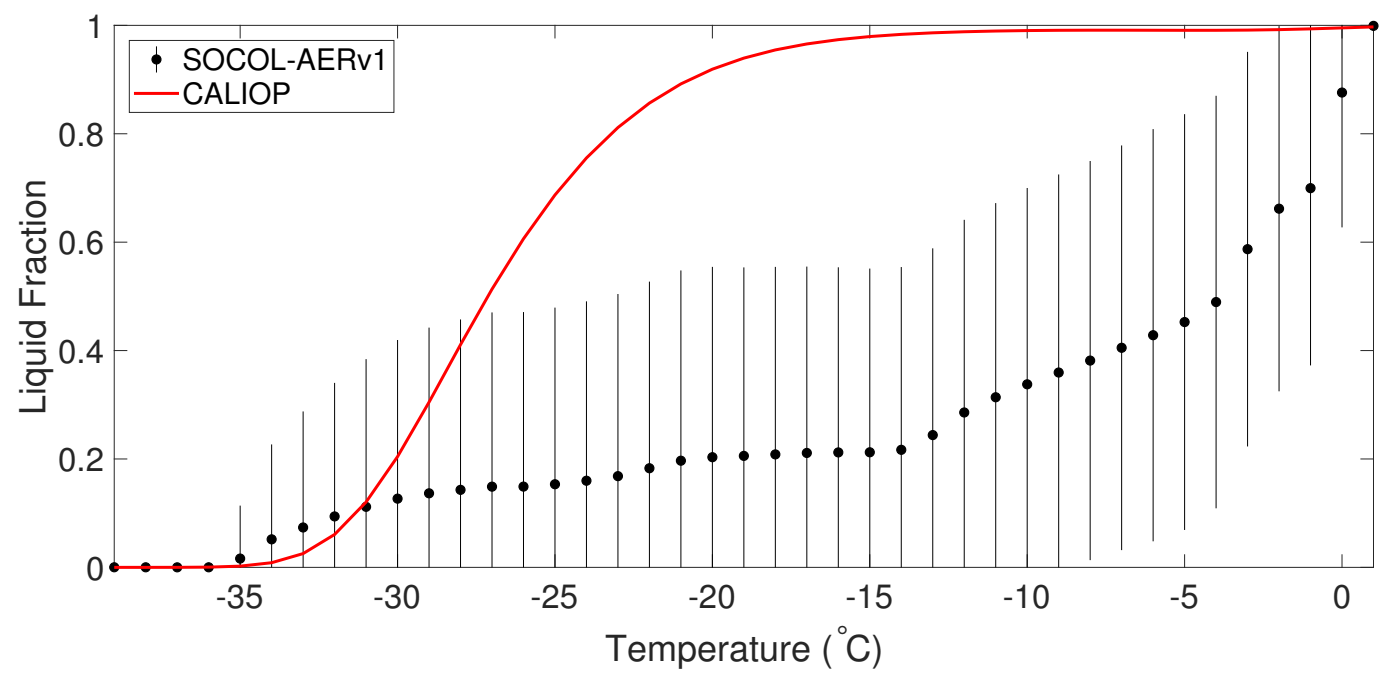

Figure S1: The liquid fraction of clouds in the mixed-phase cloud regime $\left(-38{ }^{\circ} \mathrm{C}<T<0{ }^{\circ} \mathrm{C}\right)$ simulated by SOCOL-AERv1 based on ECHAM5 during a one-year simulation (solid circles). 12hourly model output in all grid boxes with clouds is averaged in 1 degree temperature bins, with standard deviation bars included. The red curve shows the fitted sigmoid function (Hu et al., 2010) for the supercooled liquid fraction, $\mathrm{SLF}_{\mathrm{Hu}}$, derived from CALIOP Lidar measurements on board of the CALIPSO satellite. In its aqueous chemistry scheme, SOCOL-AERv2 adopts the satellite SLF to calculate the liquid water content from the model's total water content, $\mathrm{LWC}=\mathrm{SLF}_{\mathrm{Hu}} \times$ TWC. 

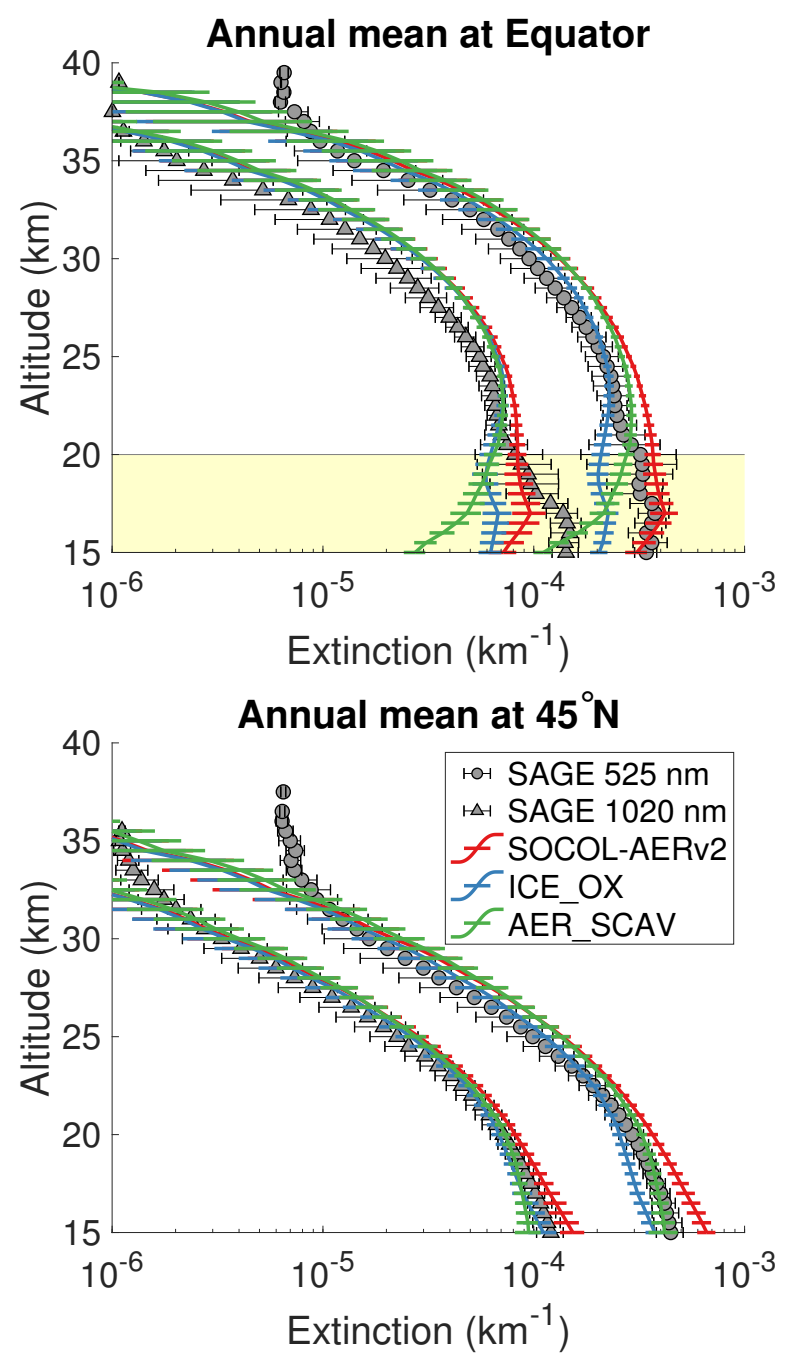

Figure S2: Comparison between annual mean model extinctions at 525 and $1020 \mathrm{~nm}$ and SAGE II measurements from the GloSSAC project (Thomason et al., 2018) at the Equator (top) and $45^{\circ} \mathrm{N}$ (bottom). Observations are averaged between 2000-2004, representing the volcanically quiescent part of the record. Model results are averaged over 5 years of the year 2000 time-slice for SOCOLAERv2, ICE_OX, and AER_SCAV. Horizontal bars represent the modelled or observed standard deviation. The highlighted region in the upper plot corresponds to the altitudes where non-sulfate aerosols may play a role. 

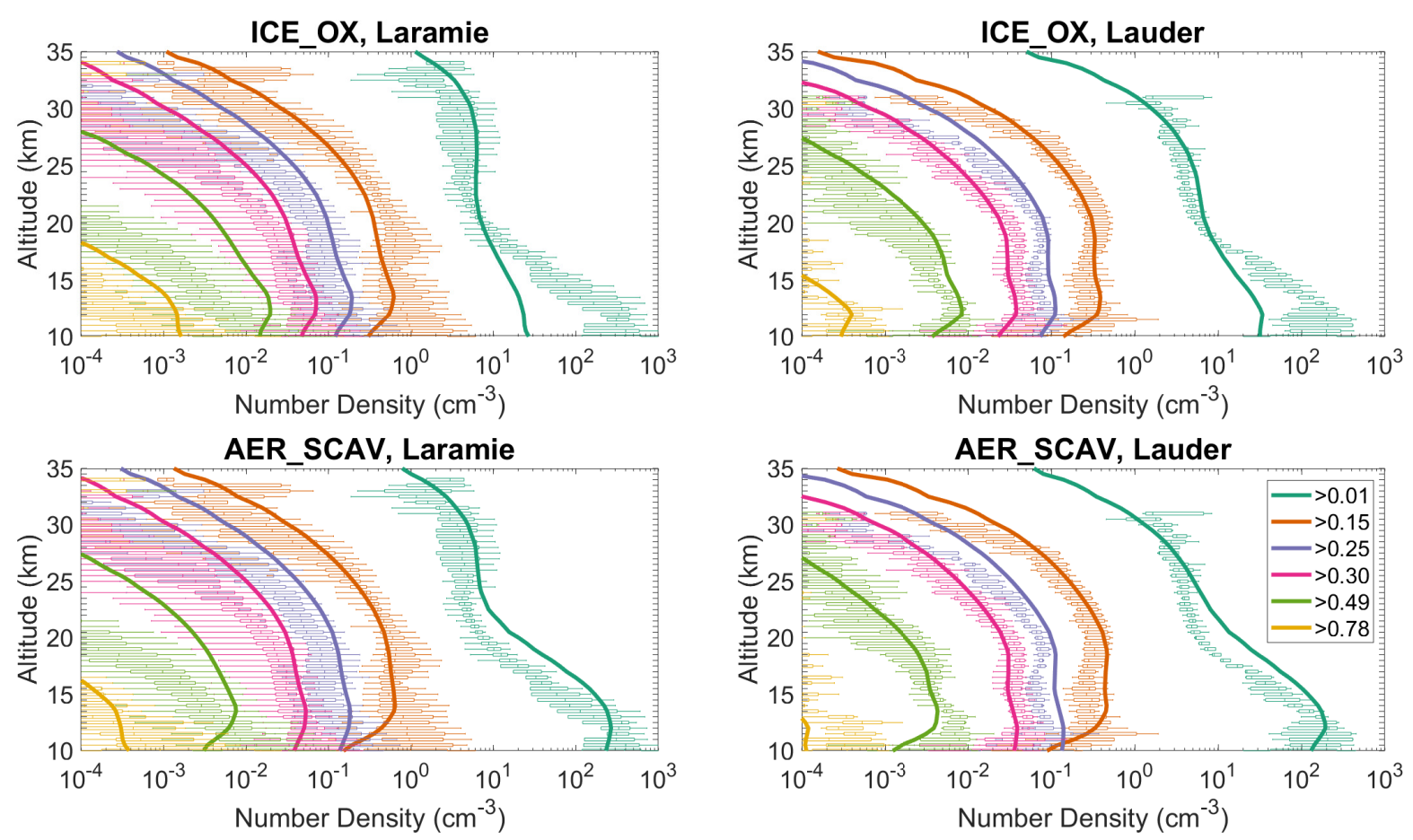

Figure S3: Number densities of particle size bins measured by OPC (Deshler et al., 2003; Deshler, 2008) and modelled by ICE_OX and AER_SCAV over Laramie, Wyoming, USA $\left(41^{\circ} \mathrm{N}, 105^{\circ} \mathrm{W}\right)$ and Lauder, New Zealand $\left(45^{\circ} \mathrm{S}, 170^{\circ} \mathrm{W}\right)$. Measured number densities are shown as box plots (minimum excluding outliers below the 0.4 percentile, $25^{\text {th }}$ percentile, median, $75^{\text {th }}$ percentile, maximum excluding outliers above the 99.6 percentile) and modelled number densities as solid lines. For the Laramie plots (left), OPC measurements are used from the period 1999-2008 and zonal mean model results are averaged over the 5 years of the time-slice. For the Lauder plots (right), OPC measurements are used from January to April 1998-2001 and zonal mean model results are averaged from January to April over 5 years of the time-slice. Model results are weighted with the counting efficiencies for OPC channels from Deshler et al. (2019) for direct comparability with the measurements. 

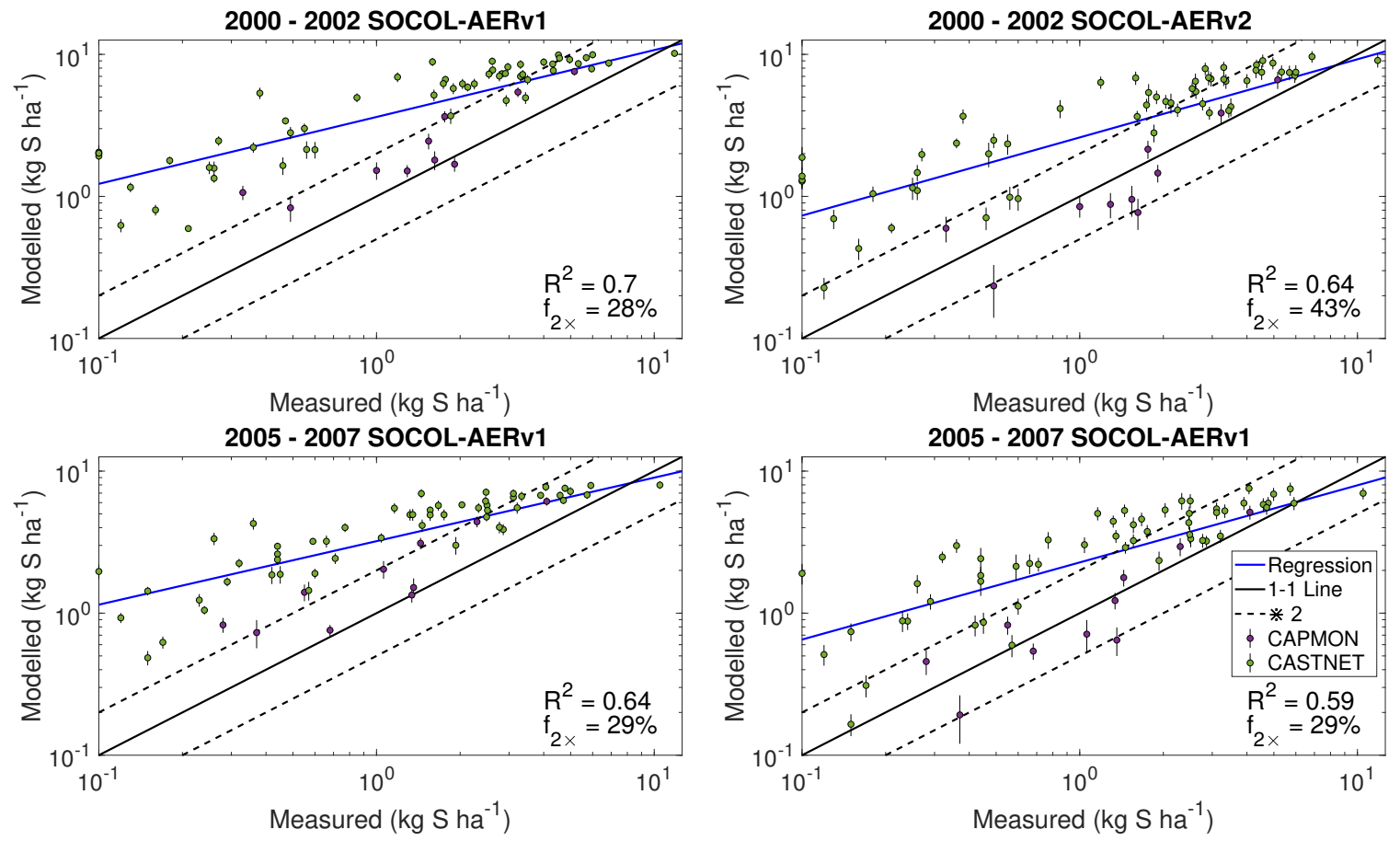

Figure S4: Evaluation of modelled $\mathrm{SO}_{2}$ dry deposition against North American measurement sites from the WMO database (Vet et al., 2014). SOCOL-AERv1 and SOCOL-AERv2 are compared with measurements in two different time periods, 2000-2002 and 2005-2007. The ensemble standard deviation for the model results is shown as vertical bars. A power regression between the simulation results and measurements is shown in blue, and can be compared to the one-to-one line shown in black. Two model evaluation metrics are listed on the plots: the goodness of fit of the power regression between model and measurements $\left(\mathrm{R}^{2}\right)$ and the fraction of sites for which the model is within a factor of 2 of measurements $\left(f_{2 \times}\right)$. Points are colored according to the measurement network of the sites. 

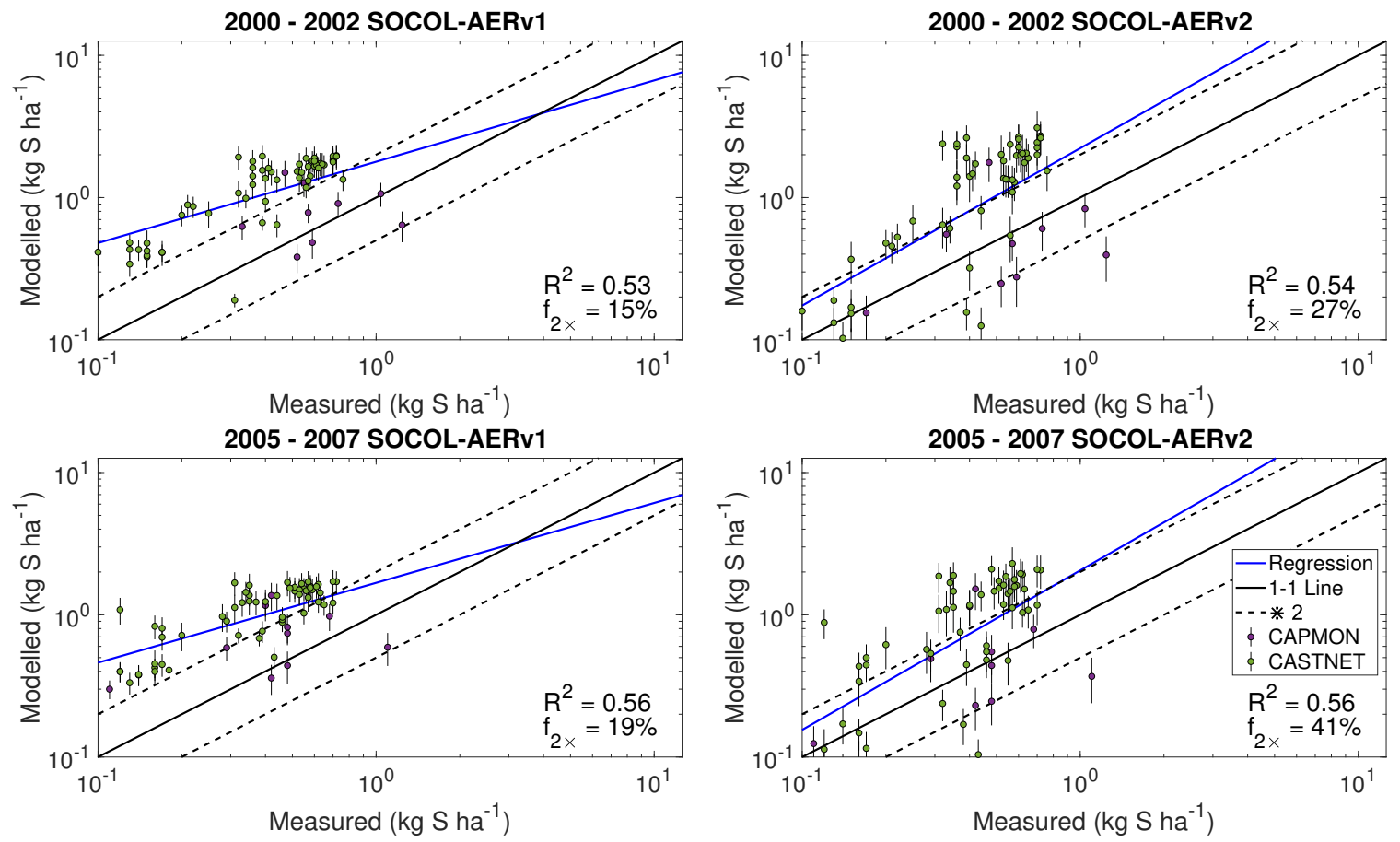

Figure S5: Evaluation of modelled sulfate aerosol dry deposition against North American measurement sites from the WMO database (Vet et al., 2014). SOCOL-AERv1 and SOCOL-AERv2 are compared with measurements in two different time periods, 2000-2002 and 2005-2007. The ensemble standard deviation for the model results is shown as vertical bars. A power regression between the simulation results and measurements is shown in blue, and can be compared to the one-to-one line shown in black. Two model evaluation metrics are listed on the plots: the goodness of fit of the power regression between model and measurements $\left(\mathrm{R}^{2}\right)$ and the the fraction of sites for which the model is within a factor of 2 of measurements $\left(f_{2 \times}\right)$. Points are colored according to the measurement network of the sites.

Table S1: The time periods covered by model intercomparison projects of sulfur deposition and this study.

\begin{tabular}{lccl}
\hline Project Name & Simulation Period & Observation Period & Reference \\
\hline Photocomp & 2000 & 2000 & Dentener et al. (2006) \\
ACCMIP & 2000 & $2000-2002$ & Lamarque et al. (2013) \\
HTAP I & 2001 & $2000-2002$ & Vet et al. (2014) \\
HTAP II & 2010 & $2009-2011$ & Tan et al. (2018) \\
SOCOL-AERv2 & $2000-2002$ & $2000-2002$ & \\
& $2000-2002$ & $2005-2007$ & This study \\
\hline
\end{tabular}




\section{S1 References}

Dentener, F., Drevet, J., Lamarque, J.-F., Bey, I., Eickhout, B., Fiore, A. M., Hauglustaine, D., Horowitz, L. W., Krol, M., and Kulshrestha, U.: Nitrogen and sulfur deposition on regional and global scales: A multimodel evaluation, Global biogeochemical cycles, 20, 2006.

Deshler, T.: A review of global stratospheric aerosol: Measurements, importance, life cycle, and local stratospheric aerosol, Atmospheric Research, 90, 223-232, 2008.

Deshler, T., Hervig, M., Hofmann, D., Rosen, J., and Liley, J.: Thirty years of in situ stratospheric aerosol size distribution measurements from Laramie, Wyoming (41 N), using balloonborne instruments, Journal of Geophysical Research: Atmospheres, 108, 2003.

Deshler, T., Luo, B., Kovilakam, M., Peter, T., and Kalnajs, L. E.: Retrieval of aerosol size distributions from in situ particle counter measurements: instrument counting efficiency and comparisons with satellite measurements, Journal of Geophysical Research: Atmospheres, 2019.

Hu, Y., Rodier, S., Xu, K., Sun, W., Huang, J., Lin, B., Zhai, P., and Josset, D.: Occurrence, liquid water content, and fraction of supercooled water clouds from combined CALIOP/IIR/MODIS measurements, Journal of Geophysical Research: Atmospheres, 115, 2010.

Lamarque, J.-F., Dentener, F., McConnell, J., Ro, C.-U., Shaw, M., Vet, R., Bergmann, D., Cameron-Smith, P., Doherty, R., and Faluvegi, G.: Multi-model mean nitrogen and sulfur deposition from the Atmospheric Chemistry and Climate Model Intercomparison Project (ACCMIP): evaluation historical and projected changes, 2013.

Tan, J., Fu, J. S., Dentener, F., Sun, J., Emmons, L., Tilmes, S., Sudo, K., Flemming, J., Jonson, J. E., and Gravel, S.: Multi-model study of HTAP II on sulfur and nitrogen deposition, Atmospheric Chemistry and Physics, 18, 6847-6866, 2018.

Thomason, L. W., Ernest, N., Milln, L., Rieger, L., Bourassa, A., Vernier, J.-P., Manney, G., Luo, 
B., Arfeuille, F., and Peter, T.: A global space-based stratospheric aerosol climatology: 19792016, Earth System Science Data, 10, 469-492, 2018.

Vet, R., Artz, R. S., Carou, S., Shaw, M., Ro, C.-U., Aas, W., Baker, A., Bowersox, V. C., Dentener, F., and Galy-Lacaux, C.: A global assessment of precipitation chemistry and deposition of sulfur, nitrogen, sea salt, base cations, organic acids, acidity and $\mathrm{pH}$, and phosphorus, Atmospheric Environment, 93, 3-100, 2014. 